\begin{tabular}{|c|c|c|}
\hline 17 & $\begin{array}{c}\text { European Association for the } \\
\text { Development of Renewable Energies, Environment } \\
\text { and Power Quality (EA4EPQ) }\end{array}$ & $\begin{array}{l}\text { International Conference on Renewable Energies and Power Quality } \\
\text { (ICREPQ'12) } \\
\text { Santiago de Compostela (Spain), 28th to 30th March, } 2012\end{array}$ \\
\hline
\end{tabular}

\title{
A Current Sharing Using Switched-Capacitor ZVS Driver for Power LEDs
}

\author{
P. H. A. Miranda ${ }^{1}$, E. M. Sá Jr. , F. L. M. Antunes ${ }^{2}$ \\ ${ }^{1}$ Federal Institute Education, Science and Technology of Ceará - IFCE \\ Campus of Sobral - Ceará, (Brasil) \\ P. Code 62040-730, e-mail: pedrohenriqbg@gmail.com, edilson.mineiro@gmail.com. \\ ${ }^{2}$ Federal University of Ceará - UFC, Group of Energy Processing and Control - GPEC PO Box 6001, \\ P. Code 60455-760, Campus do Pici, Fortaleza-CE, Brazil, e-mail: fantunes@dee.ufc.br.
}

\begin{abstract}
This paper proposes a switched-capacitor converter to source power light emitting diodes (LEDs). In contrast to conventional constant DC current drivers, the current pulse is provided by switched-capacitor LED driver. In the present driver it is possible to obtain several output circuits, where the capacitor is charged and discharged through the output circuit and the transfer of power from the grid for the LED is controlled by the switch. The effects of switching devices on the proposed converter are presented and evaluated. The experimental results demonstrated the technical feasibility of using the proposed circuit for the parallel association of LEDs, as well as to improve current sharing among LED strings. The proposed circuit driver with two output circuits presented an efficiency of $91 \%$.
\end{abstract}

\section{Key words}

Current Sharing, Power LEDS, Switched-Capacitor, SoftSwitching and ZVS.

\section{Introduction}

The energy consumed for lighting accounts for around $20 \%$ of electric energy produced in the world. Currently, light emitting diodes (LEDs - Light Emitter Diodes) are being used in many applications that previously incandescent lamps, fluorescent and other light sources were used, like, post sign, traffic lights, automotive head lights and architectural implementations. The increased penetration of the LEDs into the lighting market is due of its enhanced efficiency and extended lifetime.

In recent years, switched-capacitor (SC) DC-DC converters (also known as charge pumps) have gained increased attention. The increasing popularity of traditional SC DC-DC converters is mainly due to their unique features: they consist of only switches and capacitors, and energy transfer is achieved by controlling the charging and discharging process of the capacitors. The converters have the advantage of light weight, small size, and high-power density. Papers [1]-[7] analysed the overall of the energy efficiency of the SC converters. Moreover, against conventional understanding that power loss is caused mainly by resistance and hard-switching actions, there are also controversial claims that a bigger capacitance and a higher switching frequency can improve the overall efficiency of SC converter [8]. The traditional SC converters are designed for relatively low power. If more power is needed, usually a simple solution is to connect several SC modules in parallel.

In [9], is presented a simplified electric model of a LED, as shown as Fig. 1. The model will be used to simulate the circuit proposed in this paper. The simulator used was PSIM. From the model, it can be concluded that the voltage LED across the LED can vary according to the current variation. To simplify the design of the converter, this voltage is considered constant, because the resistance $\mathrm{R}_{\mathrm{S}}$ is small.

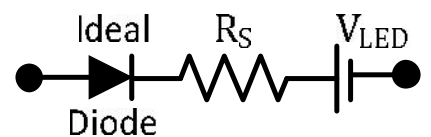

Fig. 1. Simplified electric model of the LED.

This paper proposes a SC converter using additional magnetic components to increase the efficiency and the power of the converter. The higher current conduction time in the SC is due to the use of magnetic components, making it possible ZVS (Zero Voltage Switch) commutation of the switches, which reduces the peak current through the semiconductors and increases efficiency.

The intrinsic capacitance of the MOSFETs affects switching characteristic, rising the switching losses and reducing the efficiency of the converter. In the proposed circuit an auxiliary inductance $\mathrm{L}_{\mathrm{r}}$ is used to improve switching characteristic, enabling the switching ZVS. The magnetizing inductance of the transformer helps in reducing the switching losses, increasing the efficiency of the converter. 


\section{Proposed Converter}

Fig. 2 shows the basic principle of the proposed SC converter. In a complete commutation period the capacitor $\mathrm{C}_{\mathrm{S}}$ is charged and discharged. The stored energy in the capacitor is transfer to the load.

The value of the capacitor $\mathrm{C}_{\mathrm{in} 1}$ is equal the $\mathrm{C}_{\mathrm{in} 2}$. These capacitances are much larger than the capacitance value of $\mathrm{C}_{S}$ and are used to remove any $\mathrm{DC}$ current in the transformer, shows in fig. 3. The transformer enables the galvanic isolation.

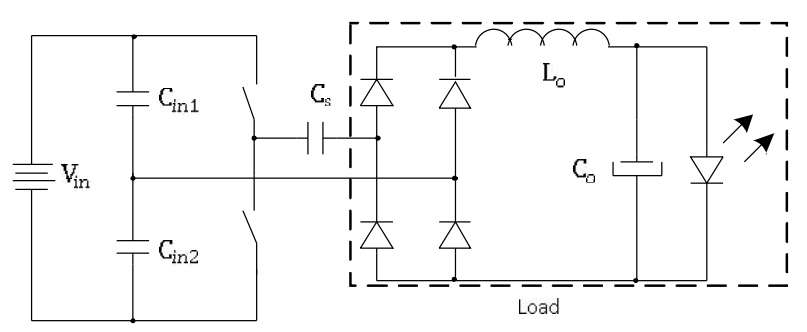

Fig. 2. Switched-capacitor LED driver circuit diagram.

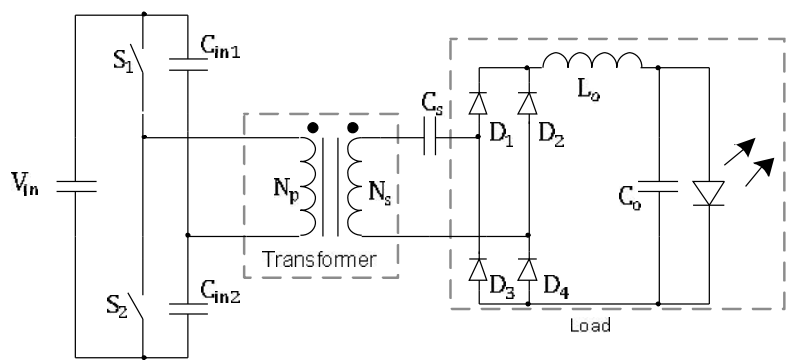

Fig. 3. Switched-capacitor LED driver circuit with transformer.

Considering the input voltage $\left(\mathrm{V}_{\mathrm{in}}\right)$ and the switch frequency constant, the average power transferred to the load is only dependent of the capacitance value of $\mathrm{C}_{\mathrm{s}}$. The inductor $\mathrm{L}_{0}$ increases the conduction time of the current in the capacitor $\mathrm{C}_{\mathrm{s}}$ and implies that the voltage in $\mathrm{C}_{\mathrm{s}}$ in fig. 1 varies between $+V_{\text {in }} / 2$ and $-V_{\text {in }} / 2$. Because of this, the voltage variation in $C_{s}$ is equal $V_{i n}$ and the voltage in $\mathrm{C}_{\mathrm{o}}$ does not influence the average power transferred to the load and the variation of LED forward voltage with temperature does not affect the power applied in the LED.

The energy stored in the capacitor in a half period of commutation is given by (1).

$$
\mathrm{E}_{\mathrm{C}_{\mathrm{s}}}=\frac{\mathrm{C}_{\mathrm{s}} \cdot \Delta \mathrm{V}_{\mathrm{C}_{\mathrm{s}}}{ }^{2}}{2}
$$

Where:

$\mathrm{E}_{\mathrm{C}_{\mathrm{s}}}-$ Capacitor energy.

$\mathrm{C}_{\mathrm{s}}-$ Capacitance switched.

$\Delta \mathrm{V}_{\mathrm{C}_{\mathrm{s}}}$ - Variation of the capacitor voltage equal $\mathrm{V}_{\mathrm{in}}$.

The average power load in a commutation period of time determined by (2).

$$
\mathrm{P}_{\mathrm{LOAD}}=\frac{2 \cdot \mathrm{E}_{\mathrm{C}_{\mathrm{S}}}}{\mathrm{T}}=\mathrm{C}_{\mathrm{s}} \cdot \mathrm{V}_{\mathrm{in}}{ }^{2} \cdot \mathrm{f}_{\mathrm{S}}
$$

Where:

$\mathrm{P}_{\mathrm{LOAD}}-$ Power load.
$\mathrm{T}$ - Commutation period.

$\mathrm{f}_{\mathrm{S}}-$ Switching frequency.

The capacitance $\mathrm{C}_{\mathrm{s}}$ can be calculated in (3), rewriting (2).

$$
\mathrm{C}_{\mathrm{s}}=\frac{\mathrm{P}_{\text {LOAD }}}{\mathrm{V}_{\text {in }}{ }^{2} \cdot \mathrm{f}_{\mathrm{S}}}
$$

The average LED power can be determined in (4).

Where:

$$
\mathrm{P}_{\mathrm{LED}}=\mathrm{P}_{\mathrm{LOAD}} \cdot \eta_{\mathrm{LOAD}}
$$

$\mathrm{P}_{\mathrm{LED}}-\mathrm{LED}$ Power.

$\eta_{\text {LOAD }}$ - Load efficiency.

Applying (4) in (3), can be obtained (5).

$$
\mathrm{C}_{\mathrm{s}}=\frac{\mathrm{P}_{\mathrm{LED}}}{\mathrm{V}_{\mathrm{in}}{ }^{2} \cdot \mathrm{f}_{\mathrm{S}} \cdot \eta_{\mathrm{LOAD}}}
$$

\section{Current Sharing with the Proposed Converter}

Several techniques have been used to reduce the problem of current sharing through parallel LED strings. One method is referred to as voltage binning. In this method LEDs are picked specifically to have similar characteristics, this causes a decreased yield and an increase in cost. In [8] a second method consists of adding series resistors to each branch. However, the addition of resistors increases the losses to the system considerably.

In [9] the problem with current sharing in the parallel association of LEDs is analyzed. Typical applications put LEDs in arrays of series and parallel elements. Individual LEDs have slightly different forward voltage drops. This difference in the voltage drops can cause different current values through each vector (LEDs in series). This current difference directly relates to output intensity of the LED. In the same paper was proposed the use of the capacitor impedance to improve current sharing. However, the load current was dependent of the voltage across the LEDs, and the input voltage should have higher values than the LED voltage.

The proposed converter is used to improve current sharing, because the voltage in $\mathrm{C}_{\mathrm{o}}$ does not influence the average power transferred to the load. However, in this converter the LEDs current does not depend on the LED voltage. The power switches of the proposed converter operate in soft switching mode, reducing the switching losses, as a consequence improving the efficiency of the converter. This lead the operation of the power switches at frequencies higher than those obtained in conventional circuits. The proposed circuit uses a transformer for electrical isolation between the LED and the input source, and enables the use of independent output circuits, as shown in Fig. 4.

Because of the transformation ratio, the switching time of the capacitor is improved and the reverse voltage applied 
to components in the output circuits are low size, thus reducing the losses and reducing the size of $\mathrm{C}_{S}, \mathrm{~L}_{\mathrm{o}}$ and $\mathrm{C}_{\mathrm{o}}$. The transformer used in the circuit can be approximated by an ideal transformer with the inductance $L_{r}$ in parallel.

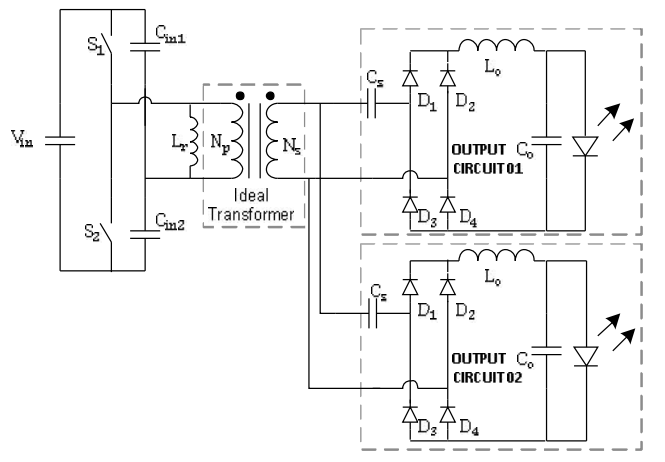

Fig. 4. Proposed converter with two output circuits.

\section{Basics of SC Converter Operation}

\section{A. Converter Circuit}

For illustrative purpose, it has been chosen for investigation in this study the circuit shown in Fig. 7. The converter is made up of two externally controlled switches $\left(\mathrm{S}_{1}-\mathrm{S}_{2}\right)$, four slow diode form the input bridge rectifier $\left(D_{1}-D_{4}\right)$, four fast diodes form the bridge rectifier after the transformer $\left(D_{9}-D_{12}\right)$, a transformer, three energy transfer capacitors $\left(\mathrm{C}_{8}, \mathrm{C}_{9}, \mathrm{C}_{11}\right)$, and an output filter formed by the inductor $\mathrm{L}_{\mathrm{o}}$ and the capacitor $\mathrm{C}_{\mathrm{o}}$ in parallel with the load.

\section{B. Topological States}

With the assumption that all the diodes are ideal, the ten operation stages of converter operation given in Fig. 5 can be are described as:

Stage 1: $\mathrm{t}_{0}<\mathrm{t}<\mathrm{t}_{1}\left(\mathrm{~S}_{1}\right.$ : on, $\left.\mathrm{I}_{\mathrm{L}_{0}} \neq 0\right)$.

At $t_{0}$, Fig. 5 (a), $S_{1}$ is conducting and $S_{2}$ is off, allowing the transfer of energy from sourceV $V_{\text {in }}$ to load. This stage ends when capacitor $C_{s}$ is fully charged.

Stage 2: $\mathrm{t}_{1}<\mathrm{t}<\mathrm{t}_{2}\left(\mathrm{~S}_{1}\right.$ : on, $\left.\mathrm{I}_{\mathrm{L}_{0}}=0\right)$.

At $t_{1}$, Fig. 5 (b), the capacitor $C_{o}$ transfer its stored energy to the load, so the current is reversed. This stage ends with the turning off of $S_{1}$.

Stage 3: $\mathrm{t}_{2}<\mathrm{t}<\mathrm{t}_{3}\left(\mathrm{~S}_{1}\right.$ : off, $\left.\mathrm{I}_{\mathrm{L}_{0}}=0\right)$.

At $t_{2}$, Fig. 5 (c), the switch $S_{1}$ is turned off under zero voltage. The voltages $\mathrm{V}_{\mathrm{C}_{\mathrm{s} 1}}$ and $\mathrm{V}_{\mathrm{C}_{\mathrm{S} 2}}$ vary linearly, since the charge and discharge of the capacitors are carried out with constant current, and therefore called linear phase-locking $\mathrm{S}_{1}$.

Stage 4: $\mathrm{t}_{3}<\mathrm{t}<\mathrm{t}_{4}\left(\mathrm{~S}_{1}\right.$ : off, $\left.\mathrm{I}_{\mathrm{L}_{0}} \neq 0\right)$.

At $t_{3}$, Fig. $5(d)$, the capacitor $C_{s}$ begins to discharge resulting in the growth of current through $\mathrm{I}_{\mathrm{L}_{0}}$. This stage ends when voltage $V_{C_{S 2}}$ is zero and $V_{C_{s} 1}$ is $V_{i n}$.

Stage 5: $\mathrm{t}_{4}<\mathrm{t}<\mathrm{t}_{5}\left(\mathrm{~S}_{1}\right.$ : off, $\left.\mathrm{I}_{\mathrm{L}_{0}} \neq 0\right)$.

At $t_{4}$, Fig. 5 (e), the voltage on the capacitor $C_{S 2}$ reaches zero, the diode $\mathrm{D}_{\mathrm{S} 2}$ begins conducting. During this step occurs the demagnetization of $L_{r}$. This stage ends when the current in $\mathrm{L}_{\mathrm{r}}$ reaches zero.
Stage 6: $\mathrm{t}_{5}<\mathrm{t}<\mathrm{t}_{6}\left(\mathrm{~S}_{2}\right.$ : on, $\left.\mathrm{I}_{\mathrm{L}_{0}} \neq 0\right)$.

At $t_{5}$, Fig. 5 (f), the current on the $L_{o}$ reaches zero. The switch $\mathrm{S}_{2}$ is conducting and $\mathrm{S}_{1}$ is off. This stage ends with the complete discharge of the capacitor $\mathrm{C}_{\mathrm{S}}$.

Stage 7: $\mathrm{t}_{6}<\mathrm{t}<\mathrm{t}_{7}\left(\mathrm{~S}_{2}\right.$ : on, $\left.\mathrm{I}_{\mathrm{L}_{0}}=0\right)$.

At $t_{6}$, see Fig. $5(\mathrm{~g})$, when the current on the $\mathrm{I}_{\mathrm{L}_{0}}$ reaches zero. The switch $\mathrm{S}_{2}$ still on and this stage ends with the turning off of $\mathrm{S}_{2}$.

Stage 8: $\mathrm{t}_{7}<\mathrm{t}<\mathrm{t}_{8}\left(\mathrm{~S}_{2}\right.$ : off, $\left.\mathrm{I}_{\mathrm{L}_{0}}=0\right)$.

At $t_{7}$, Fig. $5(\mathrm{~h})$, the switch $S_{2}$ is turned off under zero voltage and therefore called linear phase-locking $\mathrm{S}_{2}$.

Stage 9: $\mathrm{t}_{8}<\mathrm{t}<\mathrm{t}_{9}\left(\mathrm{~S}_{2}\right.$ : off, $\left.\mathrm{I}_{\mathrm{L}_{0}} \neq 0\right)$.

At $t_{8}$, Fig. 5 (i), the capacitor $C_{s}$ begins to charge resulting in the growth of the current $\mathrm{I}_{\mathrm{L}_{0}}$. This stage ends when the voltage $\mathrm{V}_{\mathrm{C}_{\mathrm{S} 1}}$ is zero and $\mathrm{V}_{\mathrm{C}_{\mathrm{s} 2}}$ is $\mathrm{V}_{\mathrm{in}}$.

Stage 10: $\mathrm{t}_{9}<\mathrm{t}<\mathrm{t}_{0}\left(\mathrm{~S}_{2}\right.$ : off, $\left.\mathrm{I}_{\mathrm{L}_{0}} \neq 0\right)$.

At $t_{9}$, Fig. $5(j)$, the voltage on the capacitor $C_{S 1}$ reaches zero, the diode $\mathrm{D}_{\mathrm{S} 1}$ begins conducting. During this step occurs demagnetization of $\mathrm{L}_{\mathrm{r}}$. This stage ends when the current through $\mathrm{L}_{\mathrm{r}}$ reaches zero.

Fig. 6 describes the corresponding component waveforms of the ten stages. The current of diode $D_{S 1}$ is naturally commutated by the antiparallel switch $\left(\mathrm{S}_{1}\right)$. Each switch is turned on at zero voltage and each diode turns off at zero current.

The commutation frequency and natural (resonance) frequency are given by (6) and (7), respectively.

$$
\begin{gathered}
\omega_{\mathrm{s}}=2 \cdot \pi \cdot \mathrm{f}_{\mathrm{S}} \\
\omega_{\mathrm{o}}=2 \cdot \pi \cdot \sqrt{\frac{1}{\mathrm{C}_{\mathrm{S}} \cdot \mathrm{L}_{\mathrm{o}}}}
\end{gathered}
$$

Where:

$\omega_{\mathrm{s}}$ - Commutation frequency.

$\omega_{0}-$ Natural (resonance) frequency.

$\mathrm{L}_{\mathrm{o}}$ - Output inductance.

The waveform in the inductor can be considered a sinusoid due to the magnetizing inductance of the transformer is calculated to allow complete discharge of the intrinsic capacitances of the switches. The current in the inductor $\mathrm{L}_{\mathrm{O}}, \mathrm{I}_{\mathrm{L}_{\mathrm{O}}}$, in the time domain, can be calculated in (8).

$$
I_{L_{o}}(t)=\left(\frac{V_{i n}}{2}-V_{o}-V_{C_{S}\left(t_{0}\right)}\right) \sqrt{\frac{C_{S}}{L_{o}}} \cdot \operatorname{sen}\left(\frac{t}{\sqrt{C_{S} L_{o}}}\right)
$$

The peak current in the inductor $\mathrm{L}_{0}$ can be calculated in (9).

$$
\mathrm{I}_{\mathrm{pk}}=\left(\frac{\mathrm{V}_{\mathrm{in}}}{2}-\mathrm{V}_{\mathrm{o}}-\mathrm{V}_{\mathrm{C}_{\mathrm{S}}\left(\mathrm{t}_{0}\right)}\right) \sqrt{\frac{\mathrm{C}_{\mathrm{S}}}{\mathrm{L}_{\mathrm{o}}}}
$$

Where:

$\mathrm{I}_{\mathrm{pk}}$ - Peak current.

$\mathrm{V}_{\mathrm{o}}$ - Output Voltage.

$\mathrm{V}_{\mathrm{C}_{\mathrm{S}}\left(\mathrm{t}_{0}\right)}-\mathrm{SC}$ Voltage in the instant initial. 


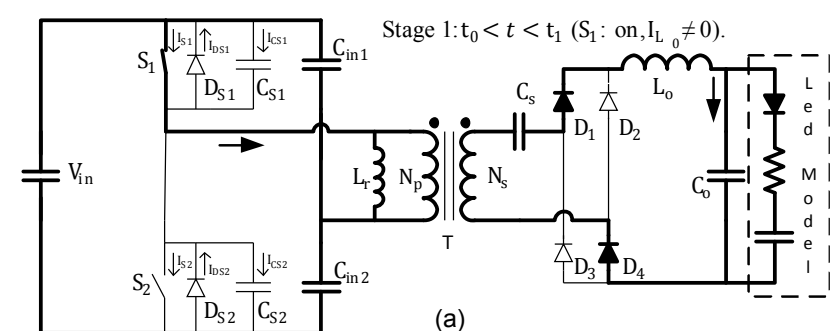

(a)

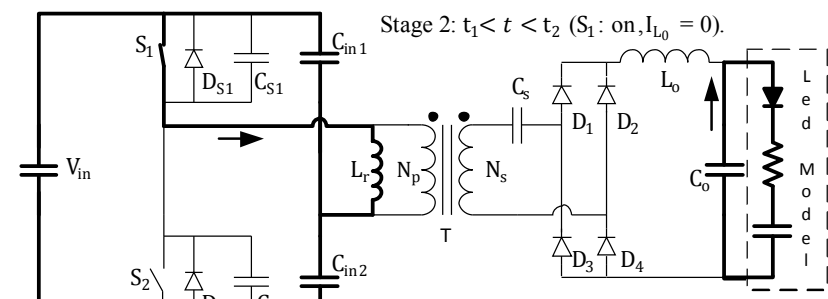

(b)

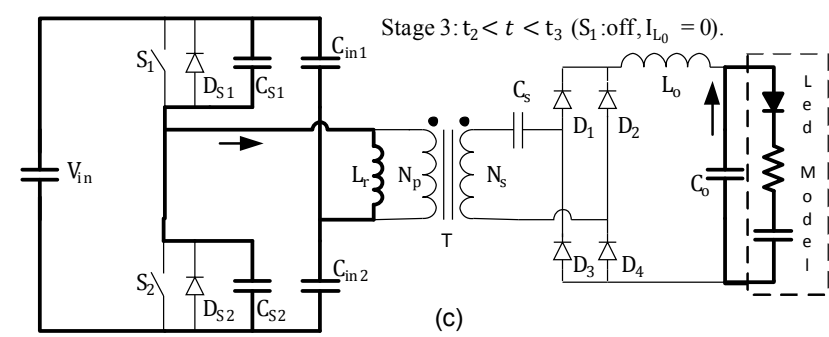

(c)

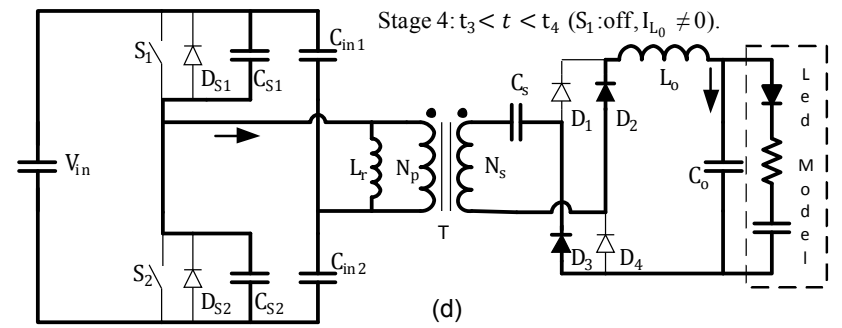

(d)

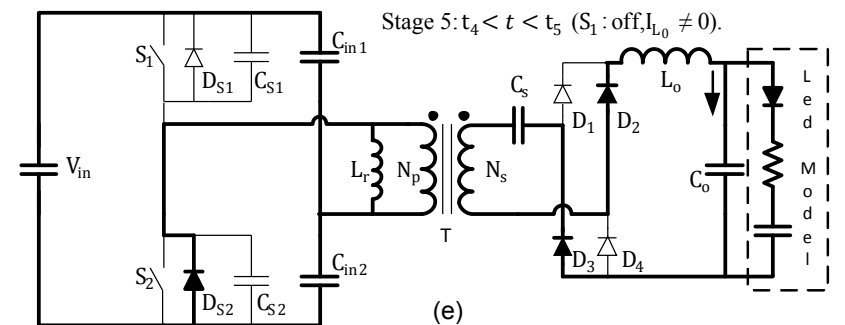

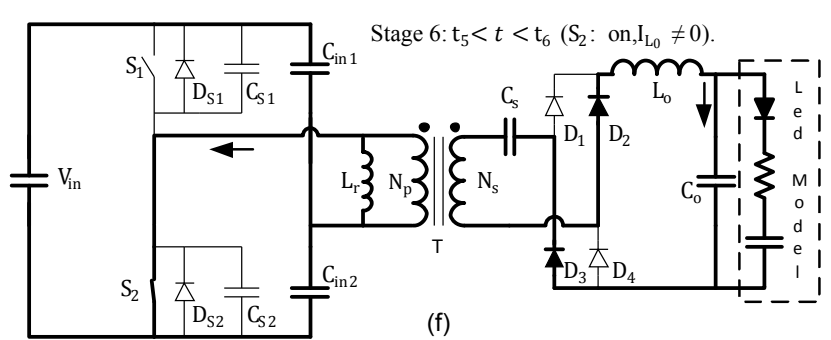

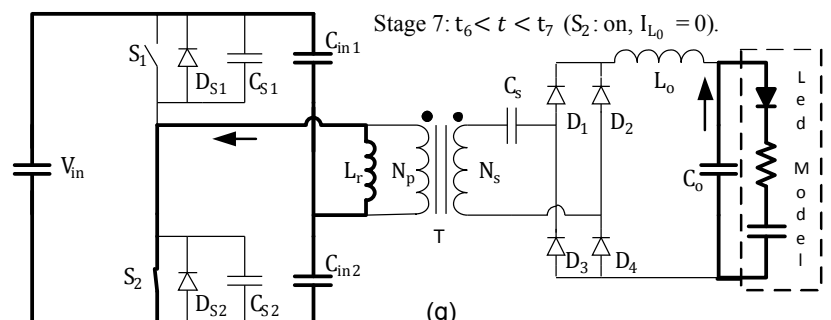

(g)

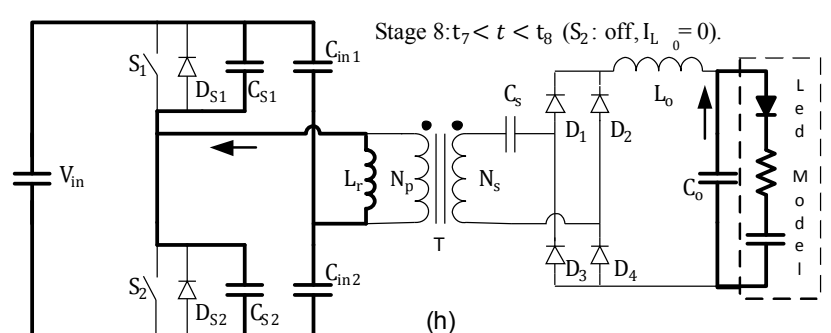

(h)
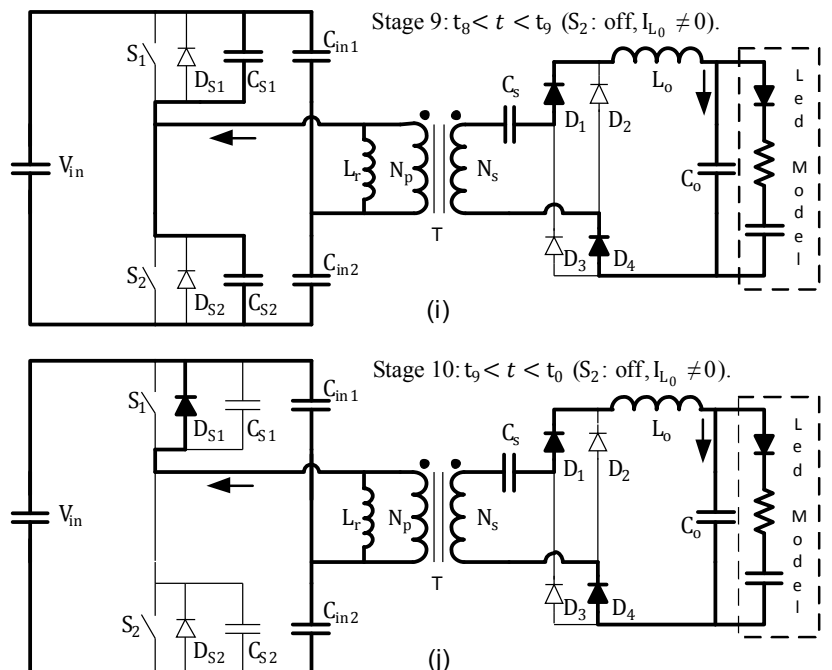

(j)

Fig. 5. Description of the ten stages of proposed converter operation.

The conduction time of the inductor, operating in critical conduction mode (MCC), thus the inductor current in (8) will be zero when the expression of the sine function is zero, can be calculated from equation (10).

$$
\begin{gathered}
\operatorname{sen}\left(\frac{\mathrm{t}}{\sqrt{\mathrm{C}_{\mathrm{S}} \mathrm{L}_{\mathrm{o}}}}\right)=0 \\
\mathrm{t}_{\mathrm{L}_{\mathrm{o}}}=\pi \cdot \sqrt{\mathrm{C}_{\mathrm{S}} \cdot \mathrm{L}_{\mathrm{o}}}
\end{gathered}
$$

The inductor will operate in discontinuous conduction mode (DCM), storing energy during part of the switching period, and transferring all that power to the load before starting the next period of operation, so the time that remains loaded the inductor is shown in equation (11), so the value of inductance should be chosen respecting the condition of the equation.

$$
\mathrm{t}_{\mathrm{L}_{\mathrm{o}}}<\frac{1}{2 \cdot \mathrm{f}_{\mathrm{S}}}
$$

\section{Design Considerations}

To experimentally validate the proposed circuit, it has been implemented the circuit shown in Fig. 7. The integrated circuit IR2153 was used as an oscillator and driver for the MOSFETs M1 and M2. With the choose values for in $\mathrm{R}_{2}$ and $\mathrm{C}_{4}$ inverter operated with a frequency of $125 \mathrm{kHz} . \mathrm{C}_{4}$ is a polyester capacitor to reduce the frequency variation with temperature variation [9]. 


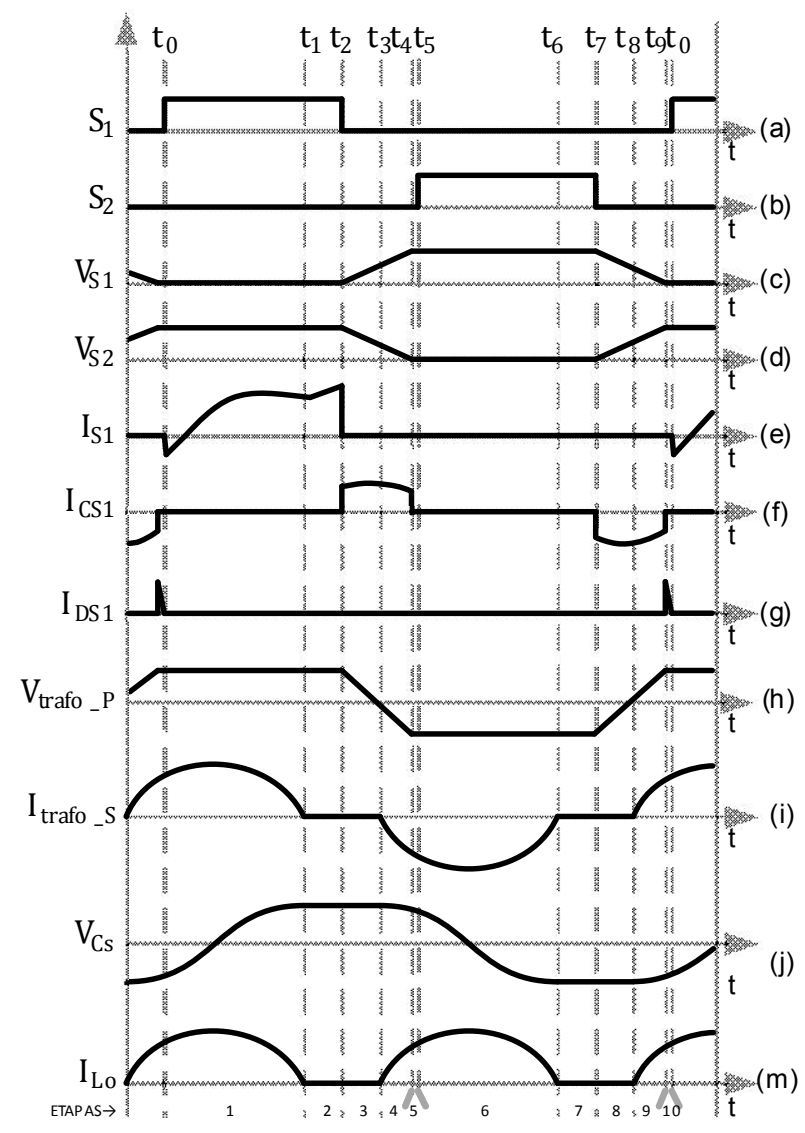

Fig. 6. Basics waveforms of the proposed converter.

For an input voltage of $220 \mathrm{~V}$, the IR2153 is usually fed through a resistor $\left(R_{1}\right)$ of $47 \mathrm{k} \Omega$, which makes this component to dissipate only $2 \mathrm{~W}$. Aiming at reducing this loss, a resistor value of $470 \mathrm{k} \Omega$ was used in configuration with a limiting diode $\mathrm{D}_{\mathrm{z} 1}$, in order to limit the voltage on $\mathrm{C}_{1}$. The power of integrated circuit system was obtained through a charge-pump circuit formed by $C_{3}, D_{6}$ and $D_{7}$ [9], which allowed increasing the yield of the circuit. For low power consumption the control circuit and the control of the switches may be responsible for a considerable part of the losses. As an example, $2 \mathrm{~W}$ of resistor losses, represent over $10 \%$ of the power in charge, for $20 \mathrm{~W}$ of output power.

The capacitor $\mathrm{C}_{3}$, besides being used in the charge-pump circuit is also used to aid the switching. This capacitor, together with the intrinsic capacitances of the MOSFETs, forms a capacitor that helps makes $\mathrm{C}_{\mathrm{eq}}$ of the equivalent circuit when the switches are blocked. with the output voltage of the inverter, the required value of the equivalent capacitor is obtained by equation $\mathrm{C}_{\mathrm{eq}}$ (11). The capacitance of $\mathrm{C}_{3}$ is calculated by subtracting the capacitance of MOSFETs. However, this capacitance to increase indiscriminately, with zero voltage switching can be compromised and the dead time the switches should be revised to allow the switch between driving voltage to zero [9].

$$
C_{\text {eq }}=\frac{I_{s w} \cdot t_{s w}}{V_{\text {in }}}
$$

Where:

$\mathrm{C}_{\mathrm{eq}}$-Equivalent capacitor.

$\mathrm{I}_{\mathrm{sw}}$ - The current at the time of switching.

$t_{s w}$ - Switching time of the switch.

The value of the input filter capacitor $\left(\mathrm{C}_{6}\right)$ was used to obtain a ripple of $20 \%$. The magnetizing inductance can be determined, taking into account that the total energy stored in the magnetizing inductance can be transferred to the intrinsic capacitors of the MOSFETs with the process of charge / discharge of the capacitor, thus the power switches can operate in soft switching mode. By considering that the energy transferred to load is small compared to energy transferred to the intrinsic capacitors, can therefore be neglected. The value of $L_{M}$ is given by equation (12).

$$
\mathrm{L}_{\mathrm{M}}=\frac{\mathrm{T}_{\mathrm{D}}}{4 \mathrm{C}_{\mathrm{eq}}} \cdot\left(\frac{1}{2 \mathrm{f}_{\mathrm{S}}}-\mathrm{T}_{\mathrm{D}}\right)
$$

Where:

$\mathrm{L}_{\mathrm{M}}$ - Magnetizing inductance.

$\mathrm{T}_{\mathrm{D}}$ - Dead time.

$\mathrm{f}_{\mathrm{S}}-$ Frequency of switching.

Fig. 8 shows the input voltage and input current in the circuit and voltage and current of an output circuit. The average value of the current through the LED was $690 \mathrm{~mA}$, the ripple factor measured was $13 \%$ and the converter switching frequency was $125 \mathrm{kHz}$. The power consumed at the input was about $45 \mathrm{~W}$. The average value of the proposed converter efficiency is $91 \%$.

Fig. 9 shows the voltage and the current of the switch $M_{2}$, demonstrating that the assembled circuit operates in soft switching ZVS. The low switching loss enables the switches to operate without the need of heat sink.

As the capacitor voltage $\mathrm{C}_{1}$ can be neglected, compared

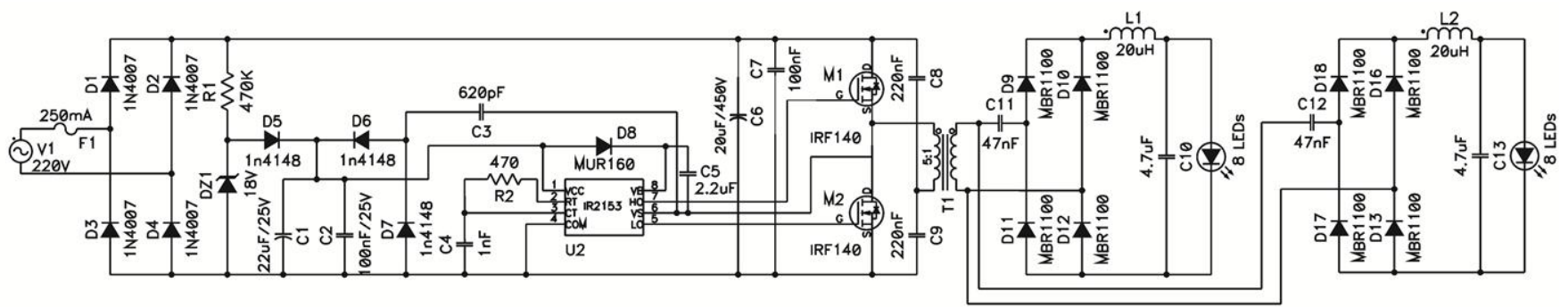

Fig. 7. Complete circuit of the proposed converter. 


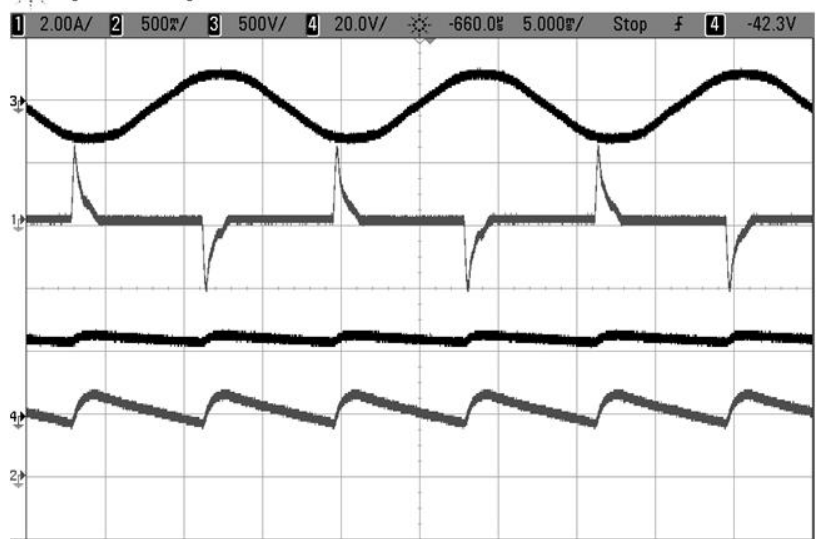

Fig. 8 - Input voltage (Ch3) and input current (Ch1) of the circuit, voltage (Ch4) and current $(\mathrm{Ch} 2)$ in the LED. (Ch3: 500V/div., 5ms/div.; Ch1: 2A/div., 5ms/div., Ch4: 20V/div., $5 \mathrm{~ms} /$ div.; Ch2: $500 \mathrm{~mA} /$ div.,5ms/div.).

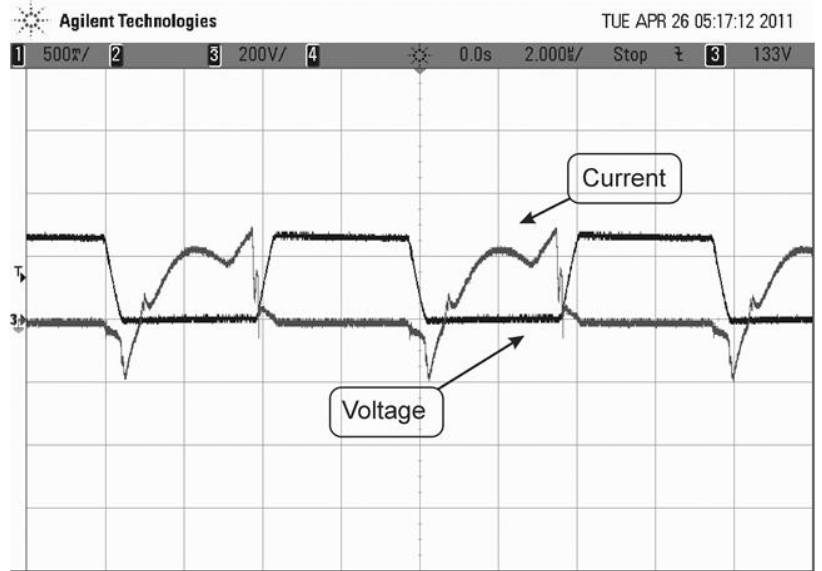

Fig. 9 - Voltage (Ch3) and the current (Ch1) in the $\mathrm{M}_{2}$. (Ch3: 200V/div., 2us/div.; Ch1: 500mA/div., 2us/div.).

Fig. 10 shows voltages and the currents in the LED in each output circuit. The small difference of the values of voltage and current in each LED circuit output is due to variations in the tolerance of the components used in circuits.

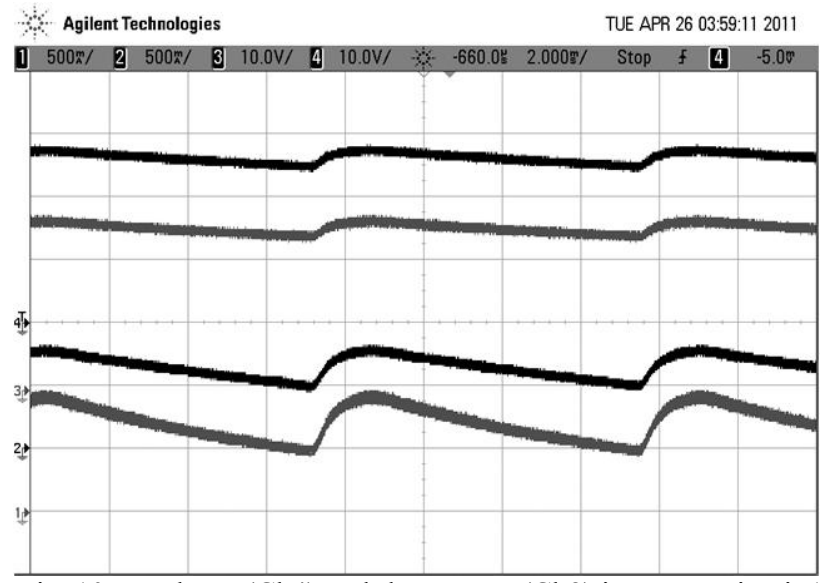

Fig. 10 - Voltage (Ch4) and the current (Ch2) in output circuit 1 , and Voltage (Ch3) and the current (Ch1) in output circuit 2. (Ch1: 500mA/div.,2us/div.; Ch2: 500mA/div.,2us/div.; Ch3: 10V/div.,2us/div.; Ch4: 10V/div,2us/div.).

\section{Conclusion}

Experimental results from a $45 \mathrm{~W}$ laboratory prototype have been carried out to demonstrate the performance of the proposed converter. The use of an SC converter provided an efficiency of $91 \%$. The proposed converter does not need a closed loop control, it operates in soft switching mode, enables the switches to operate without the need of heat sink., and promotes a converter with higher efficiency, reduced size and low cost when compared with other LEDs drivers. Consequently, there will be a detailed study of the proposed converter and in order to obtain increased converter power, more output circuits will be used, all fed from the same secondary winding.

\section{Acknowledgement}

The authors acknowledge Financiadora de Estudos e Projetos (FINEP) and Fundação Cearense de Apoio ao Desenvolvimento Científico e Tecnológico (FUNCAP) for the financial support to this work and the undergraduate students Antonio Vinícius Lopes de Oliveira, Esio Eloi dos Santos Filho and Ronaldo Portela Coutinho by collaboration in the project.

\section{References}

[1] Ng, Vincent W; Seeman, Michael D; Sanders, Seth R; "High-efficiency, 12V-to-1.5V DC-DC converter realized with Switched-Capacitor architecture," VLSI Circuits, 2009 Symposium on , vol., no., pp.168-169, 16-18 June 2009.

[2] Siew-Chong Tan; Kiratipongvoot, S.; Bronstein, S.; Ioinovici, A.; Lai, Y.M.; Tse, C.K.; , "Adaptive Mixed OnTime and Switching Frequency Control of a System of Interleaved Switched-Capacitor Converters, doi: 10.1109/TPEL.2010.2060497 " Power Electronics, IEEE Transactions on , vol.26, no.2, pp.364-380, Feb. 2011.

[3] Maity, B.; Mandal, P.; "A switched-capacitor based embedded DC-DC buck converter for high power efficiency and high power density," TENCON 2010 - 2010 IEEE Region 10 Conference, vol., no., pp.19-24, 21-24 Nov. 2010.

[4] O. Keiser, P. K. Steimer and J. W. Kolar, "High power resonant switched-capacitor step-down converter," IEEE Power Electron. Spec. Conf. (PESC), pp. 2772-2777, Jun. 2008.

[5] Henry, J.M.; Kimball, J.W.;, "Practical Performance Analysis of Complex Switched-Capacitor Converters, " Power Electronics, IEEE Transactions on , vol.26, no.1, pp.127-136, Jan. 2011.

[6] Chun-Kit Cheung; Siew-Chong Tan; Lai, Y.M.; Tse, C.K.; "A new visit to an old problem in switched-capacitor converters," Circuits and Systems (ISCAS), Proceedings of 2010 IEEE International Symposium on , vol., no., pp.31923195, May 2010

[7] Feng, W.; Shi, F. G.;, "A new switched-capacitor frequency modulated driver for light emitting diodes," Review of Scientific Instruments, vol.78, no.11, pp.114701-114701-4, Nov 2007.

[8] Baddela, S.M.; Zinger, D.S.; Parallel connected LEDs operated at high to improve current sharing. Industry Applications Conference, 2004.39th IAS Annual Meeting. Conference Record of the 2004 IEEE, Volume: 3, 3-7 Oct. 2004. Pages: 1677 - 1681 vol.3.

[9] Sá Jr., E. M. Estudo de estruturas de reatores eletrônicos para leds de iluminação. 2010. 199f. Tese (Doutorado) Universidade Federal de Santa Catarina, Centro Tecnológico, Santa Catarina. 